\title{
Erratum to: The photosensor protein Ppr of Rhodocista centenaria is linked to the chemotaxis signalling pathway
}

Sven Kreutel, Andreas Kuhn ${ }^{*}$ and Dorothee Kiefer

\section{Erratum}

After publication of our article [1] we became aware that two errors had been introduced during the revision process. These errors affect two figures (Fig. 2 and Fig. 4):

- In Fig. 2B the control panels with the nontransformed cells were wrong.

- In Fig. 4A the right panel (+CheW) was wrong.

Neither error changes the outcome of the experiments or the conclusions of the article. The corrected figures are shown as follows:
* Correspondence: Andreas.Kuhn@uni-hohenheim.de

Institute of Microbiology and Molecular Biology, Garbenstrasse 30, University of Hohenheim, 70599 Stuttgart, Germany

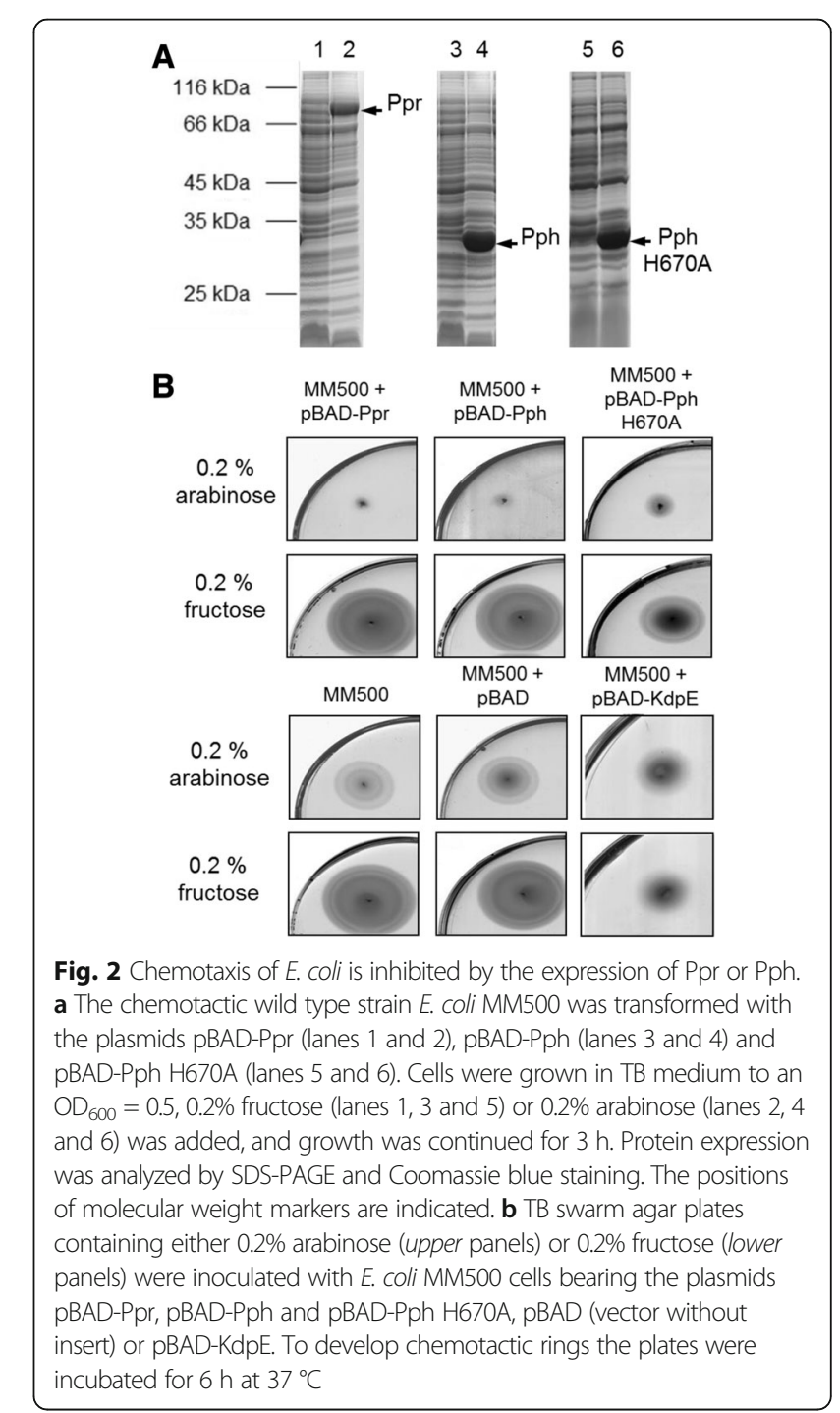




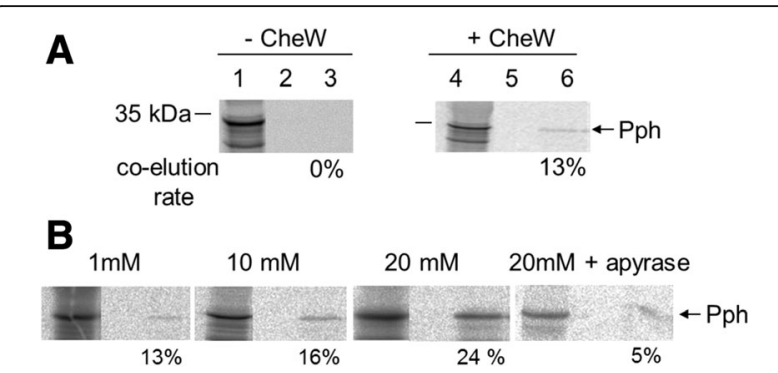

Fig. 4 Interaction between Pph and the chemotactic protein Rc-CheW. a The binding of the histidine kinase domain Pph and CheW was analyzed in pull-down assays. R. centenaria 6his-Rc-CheW was expressed in E. coli C41 cells and purified. The Pph protein was translated in vitro in the presence of $\left.{ }^{35} \mathrm{~S}\right]$-methionine (lane 1 and 4$)$. Rc-CheW was added $(50 \mu \mathrm{g}$ ) to the reaction and incubated at $37^{\circ} \mathrm{C}$. The sample was applied to a Cu-Sepharose column and after washing the bound complexes were eluted (lanes 3 and 6). The fractions were analysed by phosphorimaging. The in vitro translating protein extracts are shown in lanes 1 and 4 , the final wash steps in lanes 2 and 5 and the elution fractions in lanes 3 and 6 , respectively. The co-elution rate was calculated and is indicated. The positions of molecular weight markers are indicated. $\mathbf{b}$ The binding of the Pph protein and Rc-CheW was analysed in the presence of ATP. The Pph protein was translated and Rc-CheW was added as described in (A). ATP or apyrase was added to each reaction as indicated and the samples were analysed as described in (A). The co-elution rate was calculated and is indicated in \% as bound Pph protein

Published online: 23 August 2017

\section{Reference}

1. Kreutel S, Kuhn A, Kiefer D. The photosensor protein Ppr of Rhodocista centenaria is linked to the chemotaxis signalling pathway. BMC Microbiol. 2010;10(1):281. 